\title{
HOMEFRONT Conservation practice and global climate change
}

\author{
Jim Gulliford
}

$\triangle$ cross a broad array of scientific disciplines, the evidence is clear and compelling that global climate change is occurring. The implications of this change are important to every major industrial sector, including agriculture. Thus, it was appropriate that the Soil and Water Conservation Society's House of Delegates and Board of Directors engaged the Society in an effort to examine the science of conservation practices to mitigate and adapt to climate change and subsequent policy implications for agriculture and the sustainable management of soil and water resources.

In this issue of the Journal of Soil and Water Conservation, you can read the scientific assessment which examines how soil and water conservation practices can contribute to both the mitigation of and adaptation to climate change. The policy position of the Society, which can be found at http://www.swcs.org, outlines the importance of soil and water conservation practice, research, and outreach to address what will surely be a long, important application of science and practice to assure the future productivity of agricultural and natural resource ecosystems.

Understanding and addressing the agricultural and natural resource implications of climate change is extremely important as nations around the world face the challenge of feeding, clothing, and fueling a rapidly increasing world population from an agricultural land base that continues to be reduced at an alarmingly rapid rate. The challenge of increasing agricultural productivity and sustaining the natural resource infrastructure that supports agriculture (and is impacted by agriculture) is being influenced by short and long-term changes in weather patterns across the major agricultural production regions of the world. Our ability to meet the challenge of climate change will depend on how the agricultural sector is able to move

Jim Gulliford is executive director of the Soil and Water Conservation Society. forward to both mitigate the causes and adapt to the impacts of climate change.

By its nature, agriculture is a significant source of three major green house gas (GHG) emissions: carbon dioxide, nitrous oxide, and methane. In the same way that the individual farm and ranch contribution of nonpoint sources of water pollution add up to significant local and regional water quality problems, each farm and ranch contributes a small share of GHG emissions that in aggregate are the source of agriculture's contribution to the change in atmospheric chemistry that is fundamental to climate change.

However, there are many sound soil and water conservation principles and practices that can be applied at the individual producer scale that in aggregate can mitigate the effects of climate change and enhance the productivity and sustainability of agriculture. Practices that build soil organic matter (sequester carbon), promote energy and input efficiency, and reduce livestock methane losses can make substantive contributions to climate change mitigation and provide additional conservation and production benefits for the individual farmer or rancher.

The apparent manifestation of climate change around the world is evidenced in a variety of extreme weather occurrences. Agricultural impacts are not similar among regions but are expressed in a variety of conditions, including temperature extremes, drought, extreme precipitation events, and/or flooding. These significant changes require adaptation on the part of agriculture and individual producers to address changes in soil conditions, moisture availability, and erosion problems caused by precipitation patterns that feature more rainfall and more intense rainfall events. Proven conservation practices of irrigation efficiency, erosion control, and other management practices featuring residue management and cover crops can be of value to farmers and ranchers as they adapt to a range of climate effects now and in the future.

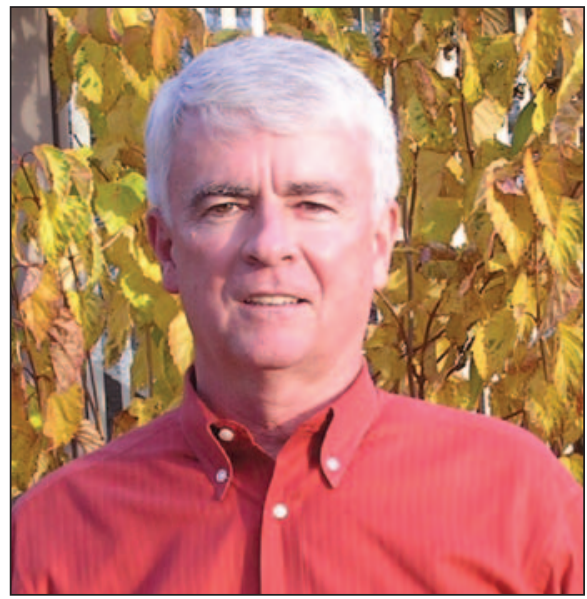

Jim Gulliford

This realization that climate change is having an impact on natural and agricultural systems is not new to the Society and its membership. In 2003, the Society published the report Conservation Implications of Climate Change: Soil Erosion and Runoff from Cropland and in 2007 published a summary report from the workshop Planning for Extremes. Both of these publications are available at http://www.swcs. org/pubs.

While many traditional erosion control and water management practices exist or can be modified to address the impact of climate change, it will be necessary for both the agricultural sector and the soil and water conservation community to lead an accelerated response to climate change. Investment in research, development, education, outreach, and application will all be critical to meeting the challenge of food security in the face of increasing population, less cultivatable land, and climate change. Research must measure and assess climate impacts on crop production and develop an entire suite of physiologi$\mathrm{cal}$ and production responses.

Crop varieties must be developed with traits that accommodate the stress of weather variability and change. Input management must take into account seasonal weather variability and increased severe weather occurrence to assure the proper form, rate, timing, and placement 
of nutrients for optimal production and environmental protection. We need to understand and be able to measure the ability of cropping systems to sequester carbon, and stable markets must be established to fairly compensate farmers for verifiable carbon sequestration. The entire set of conservation practices that have been developed to address soil and water conservation needs must be reevaluated in light of the changing conditions under which they will be applied in the future.

Finally, it is the finding of the science and policy working groups of the Soil and Water Conservation Society that the reality and challenge of climate change and its significance to agriculture, conservation practice, and world food security must be acknowledged and integrated into our conservation programs. Conservation professionals and technical service providers must be trained not only in the science of climate change, but also in the opportunities for agriculture to both mitigate and adapt. As it was in the earliest days of efforts to understand and address erosion across the landscape, the conservation professional will be instrumental to communicating the challenge and path forward to farmers and ranchers. Agriculture and its partners in private industry and government have the opportunity to address climate change, conservation, and food security in a positive, solution-oriented approach. As a Society, we stand ready to assist in this endeavor. 